\title{
CALDERÓN Y LA ÓPERA ITALIANA ${ }^{1}$
}

\author{
Maria Grazia Profeti \\ Dipartimento di Lingue e Letterature Neolatine \\ Facoltà di Lettere e Filosofia \\ Università degli Studi di Firenze \\ Via Santa Reparata, 93 \\ 50129 Firenze \\ m.profeti@tiscali.it
}

[Anuario calderoniano (ISSN: 1888-8046), 3, 2010, pp. 295-306]

\section{Comedia Áurea y libretti italianos}

Una serie de estudios ha atestiguado cómo el teatro áureo, un gran teatro de palabra, promocionado por la importancia política de una nación hegemónica, ha influido y modificado las dramaturgias nacionales europeas; aunque en tiempos sucesivos su recuerdo haya sido borrado por motivos en gran medida extra-literarios. Obviamente el papel que Calderón desempeña en este marco es muy importante, y ha sido subrayado repetidamente por la crítica $^{2}$.

1 Querida Dada, retomo un tema que he trabajado varias veces, como el más apropiado a rendir homenaje a tu interés por la ópera.

2 Para las abundantes informaciones bibliográficas relativas, ver Profeti, 2009a, pp. 147 y ss. 
Menos estudiado es un fenómeno paralelo: la presencia de libretti de ópera italianos derivados de comedias áureas, de los que he efectuado un catálogo recientemente ${ }^{3}$; de ellos cuatro son los inspirados por comedias de Calderón, cuatro los que se remontan a comedias de Lope, uno a Tirso de Molina; ocho a comedias de autores «menores»: Antonio Coello, Montalbán, Rojas Zorrilla, Salazar y Torres, Sigler de la Huerta, Antonio de Solís; añádase a estas fuentes La Baltasara, comedia de tres ingenios (como se sabe Vélez, Coello, Rojas).

Los derivados de textos de Calderón son muy significativos, ya que presentan todos los mecanismos de adaptación que se dan entre comedias áureas y libretti, como he podido comprobar.

\section{ETAPA INTERMEDIA}

Acerca de los mecanismos y las estrategias de las adaptaciones hay que subrayar que habitualmente entre libretti y comedias áureas se interponen una o más reescrituras italianas o francesas, que habían conocido ya un cierto éxito en Italia.

$\mathrm{Y}$ en efecto una etapa intermedia francesa se da en el caso del Alcaide de sí mismo: el florentino Ludovico Adimari saca un libretto, titulado Il carceriere di se medesimo, de Le geôlier de soi-même de Thomas Corneille, transposición a su vez de la comedia de Calderón. Un texto que había tenido cierto éxito en Francia, ya que había sido traducido también por Paul Scarron, con el título Le gardien de soi-même; el arreglo de Corneille se imprime varias veces, bajo el título también de Jodelet prince; y sucesivamente se traduce al holandés. Adimari parece ignorar a Calderón en su reescritura ${ }^{4}$, que se pondrá en escena no sólo en Florencia, sino en Bolonia, Turín, y hasta en Viena.

Una buena fortuna italiana del tema está atestiguada también por una traducción del texto de Scarron al italiano, efectuada por Pompeo Colonna, Príncipe de Gallicano, que había circulado en Florencia, ya que se conserva en un manuscrito de la Biblioteca Riccardiana. Posteriormente, en 1720, Antonio Salvi va a reescribir el texto de Adimari:

${ }^{3}$ Para las fichas bibliográficas, ver Profeti, 2009a, pp. 371-466.

${ }^{4}$ En efecto Adimari subraya: «Dopo i molti applausi ricevuti ne' teatri di Francia, dove già nacque, potrà vantarsi di comparir su le nostre scene»; ver Profeti, 1996, p. 149. 
recorridos complicados, como se ve, típicos de la circulación italiana de textos derivados: este es el primer dato de interés ${ }^{5}$.

Igualmente interesantes las características «literarias» de las re-escrituras italianas. En el Alcaide de sí mismo es fundamental el tema del doble: la apariencia y la realidad se reflejan la una en la otra, lo cual es muy calderoniano. Lo verdadero y lo falso funcionan en un carré en el que la mentira y el secreto cambian el ser en no-ser y el aparecer en no aparecer. El secreto de Federico está siempre a punto de ser descubierto; la salvación, para el príncipe que sabe obrar sobre la realidad, es la anfibología; la forma del contenido que la duda asume en sus palabras es, de acuerdo con el sistema calderoniano, el tema del laberinto. Para el rústico Benito, en cambio, la apariencia y la realidad se unen en el momento del sueño, aquí también según una visión calderoniana privilegiada, que permite considerar verdadero lo falso. Además, la mirada distanciada del autor vuelve constantemente a proponer al espectador el último engaño, el del teatro mismo, en una vertiginosa meta-alusión.

Es obvio que la constelación de textos derivados del Alcaide borra, como primera operación de adaptación, el tejido formal de la comedia de Calderón; y no me refiero sólo a la forma de expresión, ya de por sí lábil, y que la traducción del siglo XVII ni siquiera se propone salvar, sino a la misma forma del contenido. En los textos franceses y en el italiano no podrán tener lugar los mecanismos de la falsa apariencia que angustian a Benito (y el sueño como su pacificación); tampoco aparece la anfibología como defensa del protagonista; y por lo tanto ningún «laberinto/quimera» encarnará la forma de la duda.

La materia utilizada, por consiguiente, es sólo la diegética, desnuda ya de sus caracteres literarios y de su código simbólico. Además, una especie de simplificación prevé que el punto de vista elegido sea unívoco: la perspectiva privilegia en los textos franceses el momento bajo; hasta el punto que Corneille corta su comedia a medida del actor bufo destinado a interpretarla, Jodelet, o sea Julien Geoffrin. El texto espectáculo se inscribe tan prepotentemente en el texto literario para el teatro que llega a determinarlo: creo que la comedia de Corneille debe mucho de su éxito a la interpretación del actor que le prestó voz y acción en la escena; de hecho al título con el que el

${ }^{5}$ Profeti, 2009a, pp. 387-392. 
autor la había bautizado, Le geôlier de soi-même, se añadirá el de Jodelet prince.

Si Adimari llega, en ciertos momentos, a traducir literalmente pasajes de Corneille, el género «dramma per música» le obliga a descarnar ulteriormente la acción, que efectivamente se reduce al hueso. Otra exigencia del nuevo género es la de privilegiar las escenas «a solo» (en efecto muy abundantes) o bien a dúo, para permitir la extensión del canto. Además, un protagonista bufo rompería la perspectiva del melodrama, y por tanto Adimari hace de Benito (o Jodelet) un «Cavaliere della città di Gaeta, ma semplice», como explica el reparto. Sus ridiculeces se limitarán a la adopción de rimas insólitas o retahílas; y además su sencillez se interpretará como locura simulada, lo que naturalmente es un mecanismo que la ennoblece.

En la atmósfera «amorosa» del drama musical, muchos personajes marginales como el paje Lesbino o Odoardo, el hermano del protagonista, aparecen en escena dirigiendo un apóstrofe al dios del amor. La «cárcel» de la falsa apariencia, que encerraba al Benito de Calderón, se ha convertido ahora en una "cárcel de amor»; el engaño y la mentira como correlatos de la antinomia ser/aparecer se han convertido en las «insidie e le frodi» enlazadas en torno a «'ardir d'amante cuore». Il carceriere di se medesimo ha perdido una relación estrecha y directa con el texto fuente; mientras que en estos recorridos europeos el texto espectáculo se hace cada vez más importante: en la comedia francesa el actor Jodelet vence al autor Corneille, como hemos visto. Y el género mismo reivindica, después, todos sus derechos: el libretto se convierte en una forma que estructura de manera nueva el «tema».

\section{AdAPTACIÓN DIRECTA}

Características peculiares tienen las adaptaciones directas de textos con música españoles, efectuadas por encargo de las «cortes» de Milán y Nápoles, o de los embajadores españoles en Roma. Los textos-fuentes se deben ahora a autores de las décadas altas como el propio Calderón, Antonio de Solís, Agustín Salazar y Torres ${ }^{6}$.

${ }^{6}$ Profeti, 2009a, pp. 147-201. 
Un caso excepcional es el de Ni amor se libra de amor de Calderón, un texto palatino español "con música» (publicado en la Tercera parte de Calderón en 1664) que se representa en Roma en Palazzo Spagna, residencia del embajador español, el 24 de septiembre de 1682: una producción promocionada por Gaspar de Haro y Guzmán, Marqués del Carpio, para celebrar el cumpleaños de María Luisa, que se había casado el 25 de agosto de 1679 con Carlos II $^{7}$. Se trata de una especie de continuación de las fiestas madrileñas, para la cual el embajador elige uno de los textos representados en la corte española (donde la pieza se había estrenado en 1662). De la puesta en escena romana nos deja memoria la publicación de un «resumen» del texto de Calderón dividido en escenas, con una traducción al italiano de las arias españolas. En la loa que precede al texto, preparada para la ocasión, las cuatro partes del mundo, Asia, Africa, América, Europa, rinden homenaje a María Luisa, en una habitual cosmogonía encomiástica.

Al año siguiente, o sea en 1683, el texto se tranformó en un libretto italiano (ahora se le define "Dramma per musica»), y se representó en Nápoles bajo el título La Psiche ovvero Amore Innamorato, siempre en honor del cumpleaños de la Reina, "Compositore della Musica il Sign. Alessandro Scarlatti, Maestro di cappella della Maestà della regina di Svezia». En 1683, en efecto, el marqués del Carpio, después de haber pasado casi seis años en Roma como embajador, había sido nombrado Virrey de Nápoles, cargo que desempeñará hasta 1687. Es evidente que al proponer este espectáculo, el marqués había querido solemnizar su nombramiento, bajo la forma de homenaje a la reina. El público sería indudablemente más numeroso que en la representación casi privada de Roma; de ahí la necesidad de una re-escritura del texto.

Comparando Ni amor se libra de amor con La Psiche, nos damos cuenta de que el autor del arreglo, probablemente Giuseppe Domenico De Totis, reduce de forma drástica el texto, tanto que la fuente española parece desaparecer, aunque algunos fragmentos permiten establecer una deuda con la fuente española. El «librettista» tiene obviamente que ofrecer a cada uno de los cantantes sus "pezzi di bravura»; mientras concentra y selecciona los múltiples acontecimientos calderonianos. La reelaboración reduce las largas explicaciones de las tres

7 Profeti, 2009a, pp. 394-395. 
parejas de enamorados, y da paso a una escenografia rica e impresionante, como se puede comprobar por la inicial «lista delle apparenze». Si en la pieza de Calderón Amor llega a la escena simbólicamente sin alas ni flechas, en la napolitana hace su aparición en un carro tirado por palomas; entran después unos sátiros, seguidos por una alegoría donde aparece "Amore assistito dalle tre Grazie, Musica, Poesia e Ricchezza» (Atto II, scena VIII), en un verdadero "crescendo»: la escena IX del Atto II presenta una "Galleria ripiena di vasi d'oro e d'argento» donde entra «Psiche accompagnata da Paggi con torcie». Y el movimiento culmina con un cambio de escena «a vista», mientras Calderón cierra la II jornada concentrándose sobre la palabra poética, subrayada por la música.

Características análogas aparecen en el Fetonte, derivado directamente de El Faetonte de Calderón, melodrama del mismo Gian Domenico de Totis, que siempre Gaspar de Haro manda representar en 1685 en Nápoles para celebrar el cumpleaños de Carlos II ${ }^{8}$. El arreglo italiano presenta reducciones drásticas: por ejemplo la primera escena cuenta con 90 versos en Calderón, y con 19 en el texto italiano. No se trata sólo de una simplificación cuantitativa: todas las dobles identidades se eliminan, y se borran las referencias mitológicas entrecruzadas de Calderón. Además se acentúan los aspectos escenográficos, sobre todo en el triunfo final, donde, delante de un retrato de Carlos II, el mismo Júpiter baja en una máquina, consuela a la tierra quemada y le da un sol nuevo: el monarca español; la pieza termina con un «madrigale a cinque voci».

\section{EN EL SIGLO XVIII}

El último caso nos propone una adaptación directa más interesante aún: se trata de un curioso libretto que Gozzi escribe en la segunda mitad del siglo XVIII para un espectáculo musical que se tenía que dar en Milán, y que él sacó de Eco y Narciso; la ópera no llegó a realizarse, pero Gozzi rescató el texto del olvido publicándolo en 1772, aunque lo presenta como obra menor y de escaso interés, con los consuetos tópicos «humilitatis» ${ }^{9}$. La fuente española no se indica, y sin em-

${ }^{8}$ Profeti, 2009a, pp. 164-172 y 393-394.

9 Scannapieco, 2006. 
bargo es muy fácil de detectar, ya que Eco e Narciso, favola pastorale seriofaceta per musica sigue el esquema de Calderón ${ }^{10}$.

Naturalmente el conde veneciano tiene que reducir drásticamente el texto para adaptarse a un género distinto, que prevé el dilatarse del canto, de hecho borrando la meditación calderoniana, su ineludible percepción de la labilidad de la existencia, cuyo "memento» es el cumpleaños de Eco. Gozzi explica sarcásticamente cómo se podía entender en su tiempo un espectáculo musical ${ }^{11}$, y conforma su escritura a una serie de necesidades típicas del esquema «libretto». Así reorganiza los personajes: elimina al padre Sileno, rompe la pareja de los dos pastores, Febo y Silvio, enamorados perfectos, suprimiendo al primero, y reconstruye un duetto poniendo al lado de Silvio al cazador Anteo. No duda en modificar el mito: ahora seductor de Liríope será no el viento Céfiro, símbolo de la hybris representada por el vértigo de la altura, sino el río Cefiso.

El tejido significativo del texto español se suplanta con toques de gracia y simetría, con la propuesta de una nueva pareja femenina, «inventando» a la pastora Lisa, hermana de Liríope.Y Liríope misma (olvidado el perfil calderoniano de «mostruo humano» en la primera jornada, de madre preocupada en la segunda, y de instrumento mismo de la tragedia en la tercera) en Gozzi se porta como una damita del setecientos e intercambia cumplidos con el gracioso rústico Bato, que piensa casarse con ella.

El villano, en efecto, más sensible al dinero que a la reflexión moral como su modelo calderoniano, aunque presume de "filósofo", piensa aprovecharse de las riquezas de Liríope, a pesar de la reputación de la dama, por cierto no muy limpia. Luciani define al Bato de Gozzi

${ }^{10}$ Ver Gozzi, Opere, pp. 389-492. Me he ocupado de esta re-escritura en Profeti, 2008a, pp. 225-245; una síntesis puede verse en un trabajo en prensa en las Actas Calderonianas de Wroclaw. Las fichas bibliográficas relativas, en Profeti 2009a, pp. 392393.

11 Gozzi, Opere, pp. 393-394: «Un amico mio m'ha obbligato a scrivere un dramma per musica seriofaceto, ed egli ha desiderato che fosse, questo, atto alle decorazioni e diverso da' consueti drammi detti "buffi", che si vedono. Gli predissi che non troverebbe attori e maestro di cappella che s'accordassero co' miei bizzarri capricci. Scrissi la Favola d'Eco e di Narciso a modo mio, ed avvenne ciò ch'io avevo predetto. Per empiere questo volume io do alle stampe anche questa favola, che non comparve mai sul teatro, né per ciò intendo di pubblicar cosa meritevole e degna d'essere letta o rappresentata». 
«Truffaldin d'Arcadie» y «éducateur bouffon» ${ }^{12}$; y por cierto este inábil arrivista no tiene nada que ver con el gracioso de Calderón, cuya mirada cáustica hasta rompe las convenciones literarias de las cuales su autor se sirve.

Gozzi llega a hacer de su simbólica protagonista una coqueta de bajo nivel, fruto, como él dice, "della natura», con una perspectiva típica del siglo XVIII; mientras la de Calderón encarna una figura muy presente en la comedia áurea: la de la virgen reacia al amor, antes de conocer a Narciso; Eco será después instrumento del hado y del maleficio de Liríope, víctima del secreto dolor de la vida, que atañe a todos los personajes calderonianos. El Narciso mismo de Gozzi, en fin, es un personaje superficial, que llega a mofarse de los vaticinios de la madre.

Utilizando estas «máscaras», en relación con su propia visión de la «favola pastorale seriofaceta», como Gozzi define su texto, lo concluye con un desenlace feliz, donde el padre de Narciso, el río Cefisio, interviene como deus-ex-maquina, y así Eco y Narciso puede casarse y vivir felices y contentos.

Tan evidentes y marcadas son las diferencias entre los dos piezas que puede parecer ingenuo "compararlas», como no se pueden comparar los dos períodos culturales que Calderón y Gozzi representan. Y así podremos leer el libretto del conde veneciano como un divertissement amable y galante, espejo de su inclinación a lo fabuloso y paradójico, deudor a su tiempo de una «forma del mundo» recreativa y educativa.

\section{5. «TEXTOS CON MÚSICA» ESPAÑOLES Y LIBRETTI: ZARZUELA Y ÓPERA}

El estudio de los libretti derivados de comedias áureas nos resulta útil en una doble vertiente. En primer lugar la comparación con las fuentes nos aclara el tipo de adaptación que los sujetos españoles sufren: entre texto traducido y texto para música juegan en efecto una serie de variaciones; lo que se respeta del texto inspirador es la trama, y también la fábula (utilizando los dos conceptos de la narratología), pero se le deja al discurso la más amplia libertad.

12 Luciani, 1977, p. 770. 
En segundo lugar observemos que textos fuentes como $\mathrm{Ni}$ amor se libra de amor y El Faetonte cuentan con una presencia musical importante; forman parte de aquel subgénero llamado "zarzuela» o «semiópera»; o, más acertadamente, «textos con música» ${ }^{13}$; definiciones que los distinguen de los enteramente cantados, los únicos textos españoles que se pueden considerar "óperas», o "textos para música»: La selva sin amor (1627), de Lope, y las piezas de Calderón Celos aun del aire matan (1660), y La púrpura de la rosa (1660).

La comparación de los libretti con los «textos con música» españoles permite destacar las distintas características de los dos tipos de espectáculos musicales; no sólo porque los españoles presentan momentos alternados de dicción y canto, sobre todo de coros, y los italianos proponen un canto continuo, sobre todo solista, con imponentes coreografias y escenografias. En efecto el examen aclara, por contraste, las características de los textos originales: las estrategias de los arreglos nos ayudan a comprender la quidditas de sus fuentes.

Durante años se ha considerado que uno de los problemas «relevantes» del espectáculo musical español era su lejanía de la estructura de la ópera italiana; de esa lejanía derivaría la falta de un «origen nacional» de la ópera, que se tiene que "importar» ya en su forma definitiva ${ }^{14}$. Es un problema que se ha intentado resolver de varias maneras: subrayando la pérdida de las partituras españolas, que impide un estudio más puntual y una comparación con la música italiana, pérdida que sin duda es importante; o hablando de «menosprecio» de los españoles hacia las formas italianas, menosprecio más que dudoso, ya que resulta evidente la gran admiración y casi el complejo de inferioridad hacia la península hermana, de la cual España acepta con entusiasmo las invenciones escenotécnicas. $\mathrm{O}$ bien recordando, para justificar la falta de «arias» a la italiana en los textos para música españoles, que en España los textos son puestos en escena por «attrici che cantano e non da cantanti che recitano» ${ }^{15}$, pero creo que la razón no es sólo técnica.

13 La primera definición se debe a Stein, 1933; la segunda a Carreras, 2000, p. 94.

${ }^{14}$ Ver la presentación sintética del problema en Carreras, 1994, pp. 19-20.

15 Carreras, 1994, p. 21. 
Creo al contrario que la diferencia entre los textos con música españoles y la ópera italiana reside en la fuerte presencia en España del texto literario ${ }^{16}$, que no es susceptible de simplificaciones, en la resistencia a la esquematización, necesaria para el «dramma per musica», según indican las características de los arreglos italianos.

Por eso es impropio definir el texto literario palatino español como «anticomedia», y leerlo como "decadencia» de una fórmula experimentada por Lope en el teatro público. Texto espectáculo distinto, claro está, pero no opuesto o contrario; de ninguna manera podemos afirmar que «la palabra, que dominaba en los corrales, pierde su privilegio» ${ }^{17}$ en favor de un género nuevo.

Lope llamaba a su «égloga», en la presentación de la Selva sin amor al Almirante de Castilla, «alma» del espectáculo de palacio:

El bajar los dioses y las demás transformaciones requerría más discurso que la égloga, que aunque era el alma, la hermosura de aquel cuerpo hacía que los oídos se rindiesen a la vista ${ }^{18}$.

Pasaje a menudo malentendido, como ya subrayé ${ }^{19}$; hay que recordar, en efecto, que en la "empresa» se llamaba «alma» precisamente a la inscripción, a las palabras, y "cuerpo» a la figura simbólica unida a la parte verbal; Lope por lo tanto pone de manifiesto la necesidad de una simbiosis, no subraya una oposición, entre texto literario y texto espectáculo: si la "empresa» es unión de palabra e imagen, la ópera es unión de texto y música.

No es la "palabra» la que "pierde su privilegio» en el espectáculo musical español; todo lo contrario: es la riqueza de la forma literaria, unida a la complejidad del enredo, lo que pone en crisis la función determinante de la música; aún más alejada en la mirada meta-teatral de Calderón, que en La púrpura de la rosa ofrece hasta una lectura sim-

16 Es una hipótesis que vengo repitiendo desde 1998, pero me parece que con poco éxito.

17 Neumeister, 1991, p. 170; de nuevo en Neumeister, 2000, en las pp. 148-161 hay una lectura de Ni amor se libra de amor.

${ }^{18}$ Lope de Vega, La selva sin amor, p. 66.

${ }^{19}$ Ver Lope de Vega, La selva sin amor, pp. 20-21. 
bólica del mismo contrapunto ${ }^{20}$. Y recuérdense las recientes afirmaciones, subrayadas por el examen de la música, de Pastor Comín:

Es como si el estilo calderoniano no permitiera excesos en la fragmentación de los textos, ni en la elaboración de melismas en las partes vocales, ni ofreciera concesiones a un intenso cromatismo, pues, en definitiva, nada hubo de esto. Los madrigalismos, cuando aparecen como expresión retórica del texto no dejan de ser severos y la utilización del contrapunto se ciñe con justeza a la expresión austera de la palabra ${ }^{21}$.

Me parece evidente que en el teatro palatino de los Siglos de Oro el texto literario mantiene un valor esencial, no sólo porque en él se injertan las «mutazioni di scene», las actividades coréuticas, la música, etc., sino porque la plena comprensión-fruición sólo es posible en el espacio de la dicción, que permite al espectador descifrar el patrimonio retórico y simbólico tan importante y tan ampliamente exhibido. Ese patrimonio que los adaptadores italianos sacrifican en sus arreglos.

Y así la experiencia de un texto "todo en música», aunque sin "virtuosismi vocali, o forme chiuse che ricordino l'aria italiana» ${ }^{22}$, no llegará a desarrollarse autónomamente en España, tampoco en el espacio elitista de la corte.

20 Calderón de la Barca, La púrpura de la rosa, pp. 201-202, vv. 1447-1455; ver Profeti, 1998, pp. 109-119.

21 Pastor Comín, 2001, p. 319.

22 Carreras, 1994, p. 21. 


\section{Bibliografia}

Calderón de la Barca, P., La púrpura de la rosa, ed. A. Cardona, D. Cruichshank, M. Cunningham, Kassel, Reichenberger, 1990.

Carreras, J. J., La púrpura de la rosa, en el programa de la puesta en escena efectuada en Bologna el 12 de noviembre de 1994, pp. 19-20.

- «Celos, ópera poética de Calderón e Hidalgo», en Celos aun del aire matan, Madrid, Fundación del teatro lírico, 2000.

Gozzi, C., Opere, Venezia, Colombani, 1772, vol. V.

Luciani, G., Carlo Gozzi (1720-1806), L'homme et l'oeuvre, Lille / Paris, Champion, 1977, 2 vols.

Neumeister, S., "La fiesta de corte como anticomedia», en AA.VV., Espacios teatrales del barroco español. Calle-Iglesia-Palacio-Universidad. XIII jornadas del teatro clásico de Almagro, Kassel, Reichenberger, 1991, pp. 56-69.

- Mito clásico y ostentación. Los dramas mitológicos de Calderón, Kassel, Reichenberger, 2000.

Pastor Comín, J. J., «Ni amor se libra de amor: articulación musical del texto dramático», en AA.VV., Calderón. Sistema dramático y técnicas escénicas. Actas de las XXIII Jornadas de teatro clásico, Almagro, Universidad de CastillaLa Mancha, 2001, pp. 95-106.

Profeti, M. G., Materiali variazioni invenzioni, Firenze, Alinea, 1996.

- «Registri letterari e registri teatrali», en Calderón: testo letterario e testo spettacolo, Firenze, Alinea, 1998, pp. 83-119.

- «Eco e Narciso tra Calderón e Gozzi», en Commedia e Musica tra Spagna e Italia, ed. M. G. Profeti, Firenze, Alinea, 2008a, pp. 227-245.

- «Calderón en las reescrituras de Gozzi», en Calderón y su escuela: variacio nes e innovación de un modelo teatral, Wroclaw, 14-18 de julio de 2008b; en prensa.

- Commedie, riscritture, libretti: La Spagna e l'Europa, Firenze, Alinea, 2009a.

- «Comedia áurea y libretti italianos», en La cultura del barroco español e iberoamericano y su contexto europeo, Warszawa, 21-25 settembre 2009b; en prensa.

Scannapieco, A., Carlo Gozzi: la scena del libro, Venezia, Marsilio, 2006.

Stein, L. K., Songs of mortals, dialogues of the Gods. Music and theatre in Seventeenth-Century Spain, Oxford, Clarendon Press, 1993.

VegA, L. de, La selva sin amor, ed. M. G. Profeti, Firenze, Alinea, 1999. 